\title{
Multiple Nabothian Cysts: A Cause of Cervical Obstruction
}

\author{
Karam Harou, Affaf Elfarji, Ahlam Bassir, Lahcen Boukhanni, Hamid Asmouki, \\ Abderraouf Soummani
}

Gyneco-Obstetric Service, Mohammed VI University Hospital, Marrakech, Morocco

Email: harou.karam@gmail.com, affaf.elfarji@gmail.com

How to cite this paper: Harou, K., Elfarji, A., Bassir, A., Boukhanni, L, Asmouki, H. and Soummani, A. (2019) Multiple Nabothian Cysts: A Cause of Cervical Obstruction. Open Access Library Joumal, 6: e5212. https://doi.org/10.4236/oalib.1105212

Received: January 28, 2019

Accepted: March 15, 2019

Published: March 18, 2019

Copyright $\odot 2019$ by author(s) and Open Access Library Inc.

This work is licensed under the Creative Commons Attribution International License (CC BY 4.0).

http://creativecommons.org/licenses/by/4.0/

\begin{abstract}
Naboth cysts are common and be nign cervical lesions in women of reproductive age. They are often due to childbirth or minor trauma and are rarely symptomatic. We report the case of multiple Nabothian cysts obstructing the cervical canal in a patient with 7 years primary infertility. The diagnosis was made by MRI. Naboth cysts can mimic some benign or malignant pathologies. In case of diagnostic doubt, the biopsy is recommended to eliminate adenocarcinoma. Treatment is based on simple drainage or excision whenever cyst is symptomatic. Through this work, we will discuss some diagnostic pitfalls and the probable implication of this pathology into infertility.
\end{abstract}

\section{Subject Areas}

Gynecology \& Obstetrics

\section{Keywords}

Naboth Cyst, Cervical Cyst, Cervical Adenocarcinoma, Infertility

\section{Introduction}

Nabothian Cysts are common and benign gynecologic finding in women of reproductive age, generally without clinical significance. They are a result of the retention cyst that develops when a mucous gland of the cervix is obstructed. This retention is caused by the chronic inflammation after minor trauma or childbirth.

We will discuss through an original observation the probable implication of this entity in the context of infertility.

\section{Case Report}

A 33-year-old woman presented with primary infertility of 7 years. She had an 
irregular menstruation with oligomenorrhea. On physical examination, she didn't have any abnormalities. Transvaginal ultrasound showed multiple anechoic images located to the cervix (Figure 1).

The hysterosalpingo graphy showed distal opacification of the cervix, without opacification neither of the uterine cavity nor the fallopian tubes. A reflux of the product into the vagina at the moment of hyper pressure was noticed (Fig ure 2).

The MRI revealed multiple nabothian cysts (Figure 3).

The spermogram and cervico-vaginal smear were normal.

The hysteroscopy revealed nor mal cervical mucosa.

A cervical canal dilatation was performed by the mini 5 Fr hysteroscope which led to visualization of a normal uterine cavity. The postoperative outcome was verified by a 6 Fr catheter.

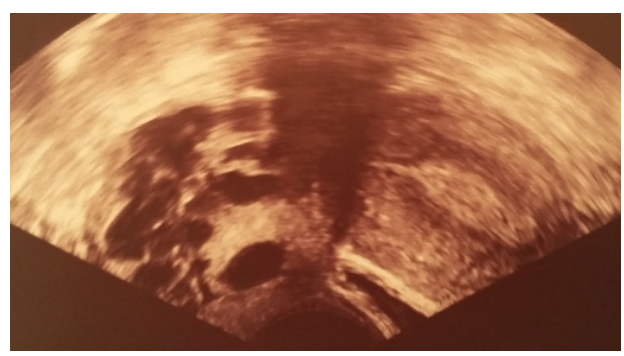

Figure 1. Anechoic images at the cervix.

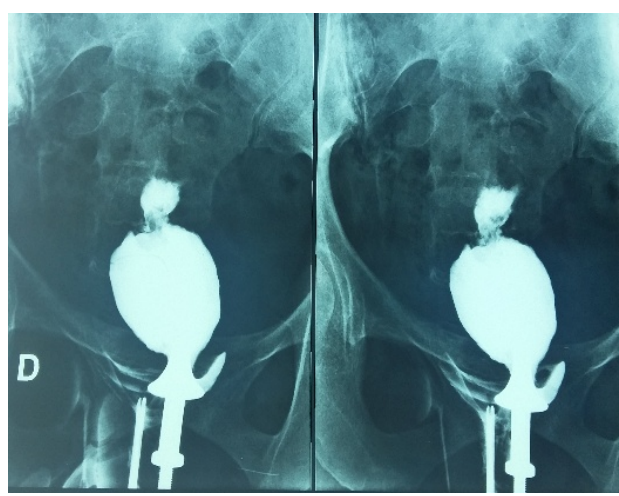

Figure 2. Distal opacification of the cervix and reflux of the product into the vagina.

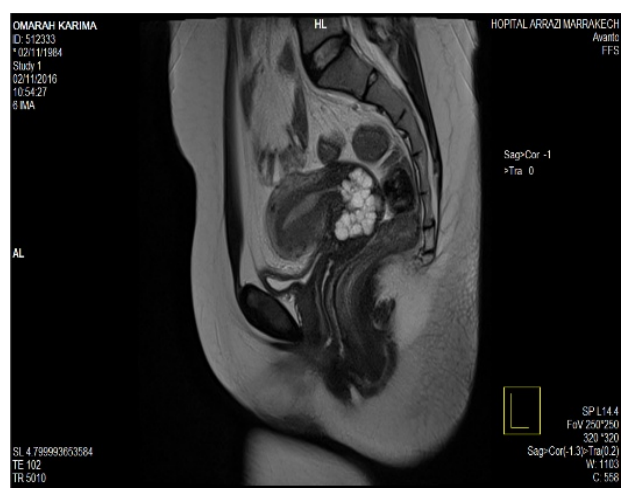

Figure 3. Multiple nabothian cysts. 


\section{Discussion}

Nabothian cysts are common and benign lesions of the cervix due to mucus retention [1]. They are generally asymptomatic and rarely reach a size above $4 \mathrm{~cm}$. Clinically, the cervix is seat of small cysts (whitish to yellow); single or multiple. Sometimes the cervix is normal in appearance.

In their symptomatic form, Naboth cysts can manifest as chronic pelvic pain, feeling of heaviness in the vagina, irregular menstruation, obstruction of the cervical canal or digestive signs following rectal compression [2] [3] [4].

Aruna et al. reported a first case in the literature of a large Nabothian cyst causing prolapse in a nulliparous female, 21 years of age [5].

Nabothian cysts may pose some diagnostic pitfalls by mimicking a polycystic ovary [6].

A cervical adenocarcinoma can mimic Nabothian cysts on MR images, hence the interest of the biopsy in any diagnostic doubt [7].

In our case, the patient consults for primary infertility and for whom the clinical examination does not show abnormalities. Would it be a case of infertility by obstruction of the cervix?

A case was reported in the literature of a spontaneous pregnancy after obstructive nabothian cyst treatment [8].

Cervicitis may contribute to infertility by fibrosis and cervical stenosis [9].

To differentiate between benign and malignant cervical lesions, some examinations are recommended such as: so nography, colposcopy, CT scan, MRI and biopsy.

Transvaginal sono graphy also affords a mean to evaluate several types of cervical masses and disorders, the probe is usually placed a few centimeter into the vagina so that the cervix can be delineated [10] [11].

CT scan is more efficient than ultrasound to evaluate these types of lesions.

MRI may accurately differentiate minimal deviation adenocarcinoma from Nabothian cysts, because the signal intensity on T2-weighted imaging in the cervical stroma is different in these two diseases. The $\mathrm{T} 1$ signal is variable ranging from isointensity to hypointensity [12] [13] [14] [15].

Naboth Cysts are often discovered on MRI.

A solid component separating or surrounding cysts is considered an index to differentiate minimal deviation adenocarcinoma (adenoma malignum) from benign lesions such as Naboth cysts. However, it is not always easy to make the difference, hence the interest of the biopsy [16].

Generally Naboth cysts do not require any treatment.

In cases where nabothian cysts are symptomatic, the treatment is based on wide excision or simple drainage [3] [5]. The main disadvantage of surgical treatment is the possibility of fibrosis, which can lead to dys pareunia [3] [17].

\section{Conclusion}

Naboth cysts are often small and asymptomatic. A great interest is in imaging for the diagnosis of these lesions. If any doubt, a biopsy is recommended to 
eliminate a malignant tumour. The involvement of Naboth cysts in infertility is possible.

\section{Conflicts of Interest}

The authors declare no conflicts of interest regarding the publication of this paper.

\section{References}

[1] Casey, P.M., Long, M.E. and Marnach, M.L. (2011) Abnormal Cervical Appearance: What to Do, When to Worry? Mayo Clinic Proceedings, 86, 147-151. https://doi.org/10.4065/mcp.2010.0512

[2] Fisun, V., Ilhan, S., Ayse, D.E., et al. (2015) Large Nabothian Cyst Obstructing Labour Passage. Journal of Clinical and Diagnostic Research, 9, QD06-QD07.

[3] Caglar, Y., Asker, Z.O., Selda, B., et al. (2009) Multiple \& Large Nabothian Cysts: A Case Report. Cumhuriyet Medical Journal, 31, 456-459.

[4] Temur, I., Ulker, K., Sulu, B., et al. (2011) A Giant Cervical Nabothian Cyst Compressing the Rectum, Differential Diagnosis and Literature Review. Clinical and Experimental Obstetrics and Gynecology, 38, 276-279.

[5] Nigam, A., Choudhary, D. and Raghunandan, C. (2012) Large Nabothian Cyst: A Rare Cause of Nulliparous Prolapse. Case Reports in Obstetrics and Gynecology, 2012, Article ID: 192526.

[6] Onur, I., Ayse, C.D., Selviye, H.O., et al. (2016) Nabothian Cysts Mimicking Polycystic Ovary in an Infertile Patient with Poor Ovarian Reserve. Journal of Cases in Obstetrics \& Gynecology, 3, 125-127.

[7] Yamashita, Y., Takahashi, M., Katabuchi, H., et al. (1994) Adenoma Malignum: MR Appearances Mimicking Nabothian Cysts. AJR, 162, 649-650. https://doi.org/10.2214/ajr.162.3.8109515

[8] Turan, G., et al. (2017) Spontaneous Pregnancy after Obstructive Nabothian Cyst Treatment. International Journal of Reproduction, Contraception, Obstetrics and Gynecology, 6, 2625-2627. https://doi.org/10.18203/2320-1770.ijrcog20172366

[9] Jennifer, M.O. and Lyudmila, M. (2016) Cystic Cervicitis: A Case Report and Literature Review of Cystic Cervical Lesions. Journal of Computer Assisted Tomography, 40, 564-566. https://doi.org/10.1097/RCT.0000000000000451

[10] Kaya, S., Ramazan, K., Özcan, B., et al. (1997) Evaluation of Nabothian Cysts with Transvaginal Sonography. Journal of Turgut Özal Medical Center, 4, 222-224.

[11] Fleischer, A.C. and Entmann, S.S. (1996) Sonographic Evaluation of the Uterus and Related Disorders. In: Fleischer, A.C., Manning, F.A., Jeanty, P. and Romero, R., Eds., Sonography in Obstetrics and Gynecology, 5th Edition, Appleton and Lange, London, 829-850.

[12] Togashi, K., Noma, S. and Ozasa, H. (1987) CT and MR Demonstration of Nabothian Cysts Mimicking a Cystic Adnexal Mass. Journal of Computer Assisted Tomography, 11, 109-112.

[13] Li, H., Sugimura, K., Okizuka, H., et al. (1999) Markedly High Signal Intensity Lesions in the Uterine Cervix on T2-Weighted Imaging: Differentiation between $\mathrm{Mu}-$ cin-Producing Carcinomas and Nabothian Cysts. Radiat Med, 17, 137-143.

[14] Sosnovski, V., Barenboim, R., Cohen, H.I., et al. (2009) Complex Nabothian Cysts: A Diagnostic Dilemma. Archives of Gynecology and Obstetrics, 279, 759-761.

[15] Wu, P.-Y., Hsu, K.-F., Chang, C.-H., et al. (2012) Ultrasonographic Diagnosis and 
Treatment of a Giant Uterine Cervical Nabothian Cyst. Journal of Medical Ultrasound, 20, 169-172.

[16] Yoshikazu, O., Yumiko, O.T., Masato, N., et al. (2003) MR Imaging of the Uterine Cervix: Imaging-Pathologic Correlation. RadioGraphics, 23, 425-445. https://doi.org/10.1148/rg.232025065

[17] Okamoto, Y., Tanaka, Y.O., Nishida, M., et al. (2003) MR Imaging of the Uterine Cervix: Imaging-Pathologic Correlation. Radiographics, 23, 425-445. 